\title{
¿POR QUÉ EL HUMOR HACE REÍR ? ? HUMOR, AMOR Y MODESTIA RITUAL EN LA LÍRICA AMAZÓNICA
}

\section{Alexandre Surrallés}

$\mathrm{E}_{\mathrm{n}}$ los poemas cantados que las mujeres candoshi interpretan durante las fiestas de tuma de masato celebradas para recibir a parientes de visita, aparecen referencias, en clave humorística, a la modestia de la cantante, llegando a veces a un abierto auto desprecio. Este artículo intenta explicar la recurrencia de estas referencias a través de la percepción candoshi de. los vinculos afectivos y de la posibilidad que sólo ofrece el humor para expresarlos.

$\mathrm{I}_{\mathrm{n}}$ the songs of Candoshi women, sung during masato feasts to receive visiting relatives, referencies appear, in humoristic code, to the modesty of the singer, which sometimes reaches self effacement. This artile attempts to explain the use of these references by means of the Candoshi perception of affective bonds and the possibility that only humor offers to express it.

A pesar de que el titulo hace referencia a la lírica amazónica, este articulo versa en particular sobre el humor en los poemas cantados candoshi. Iste hecho impone, para empezar, una precisión que se refiere a una cierta paradoja. Como es bien conocido, gracias a la labor de los medios de comunicación, el pueblo candoshi se ve afectado por una epidemia de hepatitis B v Delta agravada por una bartonelosis que está causando estragos en la población desde fines de los años 90 . La intervención de los diferentes sectores implicados en paliar el problema se está haciendo tarde $r$ de manera insuficiente. Hablar en este contexto del humor $y$ del reir puede parecer efectivamente una paradoja. Se trata por supuesto de reir para no llorar $y$ de aprorechar la ocasión para expresar un mensaje de solidaridad y esperanza con este pueblo de la : Imazonia peruana que lucha por su sobre vivencia. Lin nuero $y$ lamentable ejemplo de la larga historia de desgracias que en forma de epidemia llegan a estos pueblos con el contacto con los frentes extractiros. Lin borrador de este texto fue presentado en el seminario "Carnaval y humor ritual entre los Indios de América", yue turo lugar los dias 1, 2 y 3 de marzo del 2000 en la Casa de América de Madrid y publicado en el volumen editado por R. Piqué y. M. Ventura titulado Americia I stina, lusitoriay sociedad. Lina tisión interdisciplinaria (Barcelona, ICCI/LiAB, 20102). Quisiera agradecer los comentarios de los participantes y muy particularmente al organizador de estas sesiones, Prof. Manuel Gutiérrez. Istérez. Quisiera agradecer también a la Prof. Montserrat Ventura por sus valiosas observaciones sobre este texto. 
Desde hace algunos años me intereso en la dimensión afectiva de las sociedades amazónicas y el humor constituye sin duda una dimensión afectiva importantísima. Sin embargo, en mis trabajos anteriores nunca he abordado el tema del humor espontáneo, ni tampoco en el contexto de fiestas y rituales. Puedo decir a mi favor que en lo que se refiere al humor ritual en la sociedad candoshi, hay pocos rituales colectivos y el humor casi no interviene. No existen tampoco figuras cómicas como las conocidas en antropología con el nombre de trickster o el "tramposo " y que son tan comunes en todo el continente indígena americano. Sólo en las fiestas de toma de cerveza de mandioca o yuca (bebida conocida como masato y llamada kapuzi ien candoshi), hay momentos humorísticos sujetos a una cierta formalización, suficiente en todo caso para considerarlos humor ritual. El más notable es sin duda el momento en que las mujeres interpretan canciones entre tiernas $y$ burlescas, generalmente dedicadas a su hermano, sirviendo simultáneamente masato a los invitados. Diferentes temas pueden ser evocados en estos cantos profanos, pero uno de ellos es particularmente recurrente: las expresiones de modestia extrema de las mujeres, que a menudo se convierten en un abierto auto desprecio. Este texto pretende explorar por qué el auto desprecio femenino hace reír a los hombres y mujeres candoshi.

Empezaré por una breve presentación de este grupo, seguiré por una descripción de las fiestas para honorar a los visitantes, desde la llegada de estos hasta su partida, centrándome en el momento culminante donde se empieza a cantar estas canciones, mientras se está bebiendo. Analizaremos en concreto el tema del auto desprecio de la mujer a través de un canto traducido del candoshi, y continuaremos con un análisis de la figura humorística a la que hace referencia este canto. Para ello, el análisis debe ser incluido en el contexto de la percepción candoshi del amor $y$ de la sociabilidad entre parientes próximos.

Con una población de alrededor de dos millares de personas, los Candoshi ${ }^{2}$ forman con los Shapra una familia, que por su sentido de pertenencia

Autodenominado kandoaz̃ $i$ kandoa z y conocido también por el térnumomurato, este grupo ha sido objeto de diferentes trabajos: Amadio 1983,1985; Amadio \& D’Fmilio 1983, 1984; Surrallés 1999, Tavlor 1998. 
y por otras innumerables características debe ser incluido, a su vez, dentro del conjunto étnico jíbaro. Establecidos en los afluentes del Pastaza y alrededor del lago Musa Karusha - también conocido por Rimachi al norte de la Amazonía peruana, en el departamento de Loreto, los Candoshi ocupan un territorio habitado antiguamente por los llamados Maynas en las crónicas, de los cuales serían descendientes. Aparte de algunas actividades relacionadas con el comercio del pescado, la madera y el trabajo para la compañia de prospección petrolera a fines de los años 90, la caza y la pesca al arpón constituyen las actividades económicas masculinas por excelencia. Las mujeres, por su lado, practican la recolección y la horticultura. La subsistencia se organiza a partir de la casa, tradicionalmente construida a cierta distancia de las casas vecinas. Este aislamiento está temperado sin embargo por unas redes que asocian de diez a veinte residencias, distribuidas sobre un espacio relativamente circunscrito. Estos grupos locales se forjan a partir de la alianza de dos grupos de hermanos que se casan entre ellos como un medio de constituir lazos de solidaridad más allá de la consanguinidad. Estos grupos -unos veinte actualmente- son dirigidos por un Gran-hombre que comparte en cierta medida el poder con otro jefe. Este poder bicéfalo es el reflejo de la composición dual de los grupos locales. La relación entre estos últimos se encuentra presidida por una tensión considerable que a menudo se convierte en abierta hostilidad. El chamanismo es asimismo regido por esta lógica de oposición entre grupos. La filosofía social se fundamenta en definitiva sobre una ideología llamada « depredadora » por la antropología regional, que considera que la sustracción de personas, substancias e identidades a otros grupos es la condición para la reproducción del grupo local (Descola 1993 a, 1996; Surrallés 2000a; Taylor 1994; Viveiros de Castro 1993: 184). Las agresiones reales o simbólicas son precedidas de visiones premonitorias llamadas arutam, que los Candoshi buscan a través de largos y duros ejercicios ascéticos acompañados de la absorción de diferentes narcóticos. Estas visiones actúan sobre el lani (concepto que los misioneros han traducido como " alma », pero que en realidad hace referencia al carácter de la intencionalidad del practicante) a través del corazón, magicl,, que constituye el centro que reúne los diferentes componentes de la noción de persona. Es por esto que se le considera el punto focal de la percepción, asiento de las actividades intelectuales y facultades emotivas (Surrallés 1999). 
La hostilidad endémica que preside las relaciones entre grupos locales no impide que se realicen regularmente visitas, cuya finalidad es precisamente romper el cerco de desconfianza reinante para establecer vínculos amistosos y, si las circunstancias lo permiten, alianzas matrimoniales. Dada la incertidumbre que rodea las visitas, éstas empiezan por una ceremonia de saludo particularmente formal, extensa en duración y de gran intensidad. En lengua candoshi esta ceremonia se llama tasánomaama, forma verbal que se puede traducir por «estar cara a cara». Empieza con la llegada de los visitantes que anunciarán su presencia sonando un cuerno de caza o soplando el cañón del fusil. Fingirán pasar por alli sin intención de visita y simularán avanzar remando con sus canoas a contracorriente del río. Permanecerán sin moverse, a la espera de una señal de los dueños de casa. Los visitantes se habrán ornamentando con coronas de plumas, pinturas faciales y todos los demás atuendos de las grandes ocasiones. Los de la casa aprovecharán estos instantes para adornarse también. Una vez listos, invitarán a los visitantes a estacionar sus canoas y subir hasta la residencia que normalmente se encuentra un poco alejada de la orilla. Los visitantes masculinos se presentarán con el fusil cargado al hombro, en fila y por orden de rango. El jefe de los visitantes saludará al jefe de la casa con un sucinto "tamarimta» ( ¿estás vivo?) a lo cual este último les invitará a acceder bajo el tejado. Habrá un silencio tenso hasta el momento mismo en que se miren a los ojos fijamente, habiendo evitado cruzar miradas hasta entonces.

A continuación, el dueño de la casa romperá el hielo con unas frases preliminares que hacen referencia a las buenas costumbres $y$ a la tradición para, enseguida, empezar a vocalizar una especie de canto de una sorprendente vivacidad rítmica y energía fónica. Se trata de variaciones improvisadas de fórmulas estereotipadas cuyo contenido concreto es muy escaso, hecho que no impide que la intervención se prolongue, incluso hasta llegar a una media hora por participante. A esta primera intervención, el jefe de los visitantes le responderá de la misma manera, a lo cual le replicará quién le sigue en importancia de la casa ! así sucesivamente, hasta que todos los hombres adultos presentes havan participado. La ceremonia puede extenderse durante varias horas, pero todo lo que se dirán será simplemente 
que es importante visitarse. Evitarán mencionar los verdaderos objetivos de la visita así como cualquier otro tema substancial. En otras palabras, se habla mucho para no decir gran cosa.

El análisis de esta ceremonia no la desarrollaré aquí (ver Surrallés 2000 b). Sólo diré que una vez hechos los saludos, se disipa la fuerte tensión inherente a todo encuentro de ese tipo en territorio candoshi. Hay que pensar que cada familia vive en un aislamiento considerable, que las distancias son enormes $y$ difíciles de recorrer, que la densidad de población es baja y que, por si todo esto fuera poco, un desconocido es un enemigo potencial en una sociedad a menudo sumida en rendettas.

Después de la ceremonia de saludo se empieza a servir el masato preparado para la ocasión; es el inicio de la fiesta propiamente dicha. Ésta se prolongará hasta que las dos o tres tinajas llenas de unos 30 litros de cerveza de yuca fermentada se havan consumido. Durante el día se beberá hasta la ebriedad y se dormirá por la noche. Muy temprano, antes del amanecer, los hombres serán convocados cerca del fuego, en la parte femenina de la casa de ordinario, para tomar una infusión de una planta llamada vajoosa (Ilex sp.) que tiene efectos eméticos. Sin las pinturas faciales, ni los adornos, ni el resto de la parafernalia propia de las visitas, los hombres se entregarán a una conversación intimista donde evocarán los verdaderos temas de interés de la visita: el establecimiento de vínculos de alianza matrimonial y/o guerrera, los intercambios comerciales o de servicios, las demandas de información relacionadas con los conflictos, etc. La reunión se terminará en el momento en que los congregados se dirijan por separado al río a bañarse y vomitar la infusión que han estado bebiendo. Después de ornamentarse de nuevo, se instalarán otra vez en sus asientos en la parte masculina de la casa para empezar otro día de toma abundante de masato, pudiendo pasar asi varios dias, hasta que la bebida se termine.

Lno de los momentos culminantes de la fiesta es cuando los participantes, llevados por la cuforia producida por el masato, empiezan a cantar y a tocar los instrumentos musicales. Los cantos profanos son 
interpretados públicamente, en parte improvisados, aunque siguiendo siempre el canon del género musical en cuestión. Hombres y mujeres pueden cantar solos o también en polifonía. Otras veces el cantante es acompañado por la flauta pentatónica de dos agujeros, por el violín de fabricación casera que produce un sonido continuo, o por el tambor. La música profana candoshi es de una gran riqueza, belleza y profundidad. Las letras de las canciones evocan sentimientos líricos expresados a menudo mediante alegorías de la vida animal u otros hechos del entorno natural. La plenitud de la juventud, las formas y los colores de la vida, el amor, la amistad, el paso del tiempo, el dolor del adiós, son algunos de los temas clásicos de estos cantos, temas que a veces aparecen conjuntamente en un mismo poema como es el caso de esta breve tonada interpretada por Isigoro, el dueño de la casa donde vivía durante mi estancia en la parte oriental del territorio candoshi, cuando se enteró que una mujer a la que amaba, contrajo matrimonio:

\section{Yo soy' como la boja colgando de la rama de un árbol,} vendrá un viento tan fuerte que me llevará y me dejará quién sabe dónde, quizá alli seré feliz:

(Cantado por Isigoro, hombre del alto Nucuray, diciembre del 1992.)

Otras veces, las canciones hacen referencia más directamente a la bebida y a las fiestas que tienen lugar para recibir una visita. El poema siguiente es la traducción de un canto interpretado cuando bajábamos por el río en canoa, completamente ebrios, después de despedirnos de una familia donde habíamos estado bebiendo durante tres días. Nadie en la canoa era capaz de remar, apenas de mantener el rumbo para no enredarse con la vegetación de la orilla, con el consiguiente riesgo de volcar. Daua, el jefe de esta expedición, tomó la flauta y tocó una melodía que luego cantó. La letra empieza diciendo «soy como un guacamayo» y, de hecho, Daua llevaba una imponente corona de plumas azules y amarillas de esta ave. La canción habla de los viajes y de las visitas. El fruto de la palmera chambira (Astrocaryum cljambira) representa el masato. El poema termina con una referencia a la muerte y al paso del tiempo, una constante del existencialismo melancólico de la lírica candoshi. 
Yo soy como el guacamayo

que vengo de muy lejos

cuando el ivento sopla muy fuerte, me lleva hasta aquí.

Estoy ahora aqui

buscando un árbol imponente para posarme

nunca el guacamayo se posa en cualquier sitio

se posa siempre en un árbol bien alto.

Yo bago igual,

de igual manera, vengo a visitarles.

Yo soy como el guacamayo, siempre buscado el fruto de la palmera chambira, si encuentro el fruto de chambira, puedo comerlo y beber su jugo, pero el día que moriremos, como el guacamayo, vamos a desaparecer que sé yo quién, si tú o yo, será el primero.

Yo soy como el guacamayo que viene de muy lejos, ¿de donde viene el guacamayo? Sin duda de muy lejos.

(Cantado por Daua, hombre del Alto Nucuray, diciembre del 1992.)

Para las fiestas, uno de los géneros más apreciados de la música profana es el de las canciones dedicadas al hermano, al marido y a veces a un visitante especial, que las mujeres interpretan dando de beber al homenajeado masato a bocajarro. Estos cantos son llamados yashina en candoshi, término derivado de yashisi (que quiere decir precisamente yuca o mandioca) y de la forma verbal yashimaama (que quiere decir, al mismo tiempo, «ofrecer masato» $y$ «cantan» en el contexto de estas fiestas). Estas canciones aparecen en el momento culminante de la fiesta, cuando se pasa de la euforia a la melancolía y donde uno no sabe si ríe o si llora. Este momento donde el gozo de la compañía de los visitantes queridos empieza a dejar paso al sentimiento de desolación por despedida. Los temas de estas canciones utilizan imágenes poéticas semejantes: el amor fraterno o conyugal, la muerte que nos separará, el masato que estamos compartiendo, la suerte de podernos visitar, etc. El humor interviene a menudo en estos cantos femeninos. Y, con mucha frecuencia, este humor se sirve del auto desprecio de la cantante frente a sus invitados. En la siguiente traducción podemos apreciar uno de estos 
cantos, dedicados al hermano, interpretado por una mujer de edad avanzada, en una de las primeras fiestas donde tuve ocasión de participar. Esta mujer venía viajando con su marido y coincidimos en la casa de su hermano, que me acogía por unos días. Era ya de noche y su canto estaba acompañado por una flauta.

Hermano, bermano mio, toma mi masato aungue no esté demasiado fuerte. Hermano, bermano mio, no conocemos el momento de nuestra muerte; cuando mueras, me acordaré que a ti te ofrecia bebida, a ti bermano mio, asi me acordaré de ti cuando estés muerto.

El bombre muere siempre demasiado temprano, the eres mi unico bermano, cuando mueras me acordaré de este momento en que te be senido masato cara a cara. Hermano, bermano mio, si fuéramos desconocidos, no te invitaria a beber; pero como tui eres mi propio bermano, yo lo bago de esta manera.

He venido de muy lejos; cuando me vaja, me diré que be cumplido mi palabra convidándote a beber (bis)

Hermano, bermano mio, asi lo bacian nurestros ancestros,

bermano, bermano mio, toma mi masato aungue mi brazo se parezca al de un maguisapa.

(Cantado por Tsirta, mujer del alto Nucuray, enero del 1993.)

El humor interviene al final del canto en el momento en que Tsirta, después de cantarle a su hermano con un tono agudo de voz que expresa cariño y ternura, le dice que tome su masato aunque su brazo parezca al del mono maquisapa (primate conocido también como mono araña y cuyo nombre cientifico es Ateles belzebuth). No se puede entender la ocurrencia humorística sin conocer la anatomía del brazo del maquisapa y más concretamente su musculatura. El tríceps, el músculo de la región posterior del antebrazo, le cuelga visiblemente, sobre todo cuando está distendido, es decir cuando el brazo está estirado. El humor juega con el parecido que puede haber entre el brazo de este primate y el de una mujer anciana. Quizá por todos los años dedicados a realizar con gran esfuerzo los quehaceres domésticos y agrícolas, los brazos de las ancianas candoshi presentan este fenómeno, aunque sea caricaturesco compararlo con los brazos de estos 
monos. Si esto es lo que tiene gracia para los oventes cabe preguntarse :por qué es necesario, para hacer reír, que la mujer se minusvalúe a sí misma evocando las marcas que la senectud deja en su cuerpo? Esta pregunta es pertinente porque el menosprecio femenino de sí misma aparece en diferentes contextos de la sociabilidad candoshi, sin una contrapartida masculina. A mi entender, el sentido de esta configuración humorística y afectiva puede explorarse a partir de la idea candoshi del amor en el seno de la sociabilidad familiar.

Para explorar la concepción candoshi del amor empezaré proponiendo una hipótesis en base a una relación semántica. Para decir «amar» en lengua candoshi se utiliza la forma verbal «clinamaama». La raíz de esta forma verbal, "clsin-», se encuentra en todas las palabras relacionadas con el amor; pero no exclusivamente. Ella aparece en todos los términos relacionados con lo que podríamos llamar la familiarización, como por ejemplo la familiarización por adopción de animales salvajes o domesticación ${ }^{3}$. Veamos esto con detenimiento:

Es una práctica habitual de los cazadores recoger las crías que deja un animal cazado. Crías de aves de todo tipo, de primates así como de otros tipos de mamíferos aparecen en la casa regularmente. La subsistencia de estos huérfanos retirados de su medio natural depende de los cuidados de la nueva familia adoptiva humana. En esta sociedad, la relación entre estos animales adoptivos y sus cuidadores son la imagen misma del cariño y la ternura. Las mujeres, que son las esposas, las hijas o las hermanas del cazador, toman la responsabilidad de cuidar estos animalitos con una dedicación casi tan intensa como si fueran sus propios hijos. Amamantan a los mamíferos, dan de comer a los pájaros y mastican la comida para todo animal que no ha desarrollado aún la dentición. Todos estos cuidados

F. sentido etimolisgico de la palabra domesticación (del griego «domos», casa) es precisamente éste: llevar a la casa. Para un análisis más extenso de este paradigma ver Surrallés 1998. Para un análisis de los cantos de amor achuar, grupo étnico que habita al norte de los Candoshi, ver Taỵlor 1983. 
permiten que esta cría indefensa y desamparada supere con éxito la fase crítica de adaptación y pueda desarrollarse normalmente.

La forma verbal xápshigámaama significa " acostumbrarse » o "familiarizarse » y se utiliza para hacer referencia a este proceso delicado que es la domesticación de animales familiares. Ahora bien, esta forma verbal se utiliza también en muchos otros contextos que nada tienen que ver, en principio, con la vida animal. Los huérfanos humanos cuando son adoptados, también «se familiarizan» con su nueva familia de acogida, usando esta forma verbal. De hecho, este término proviene de mxápshi que quiere decir "huérfano». Los orfandad es un fenómeno importante en la vida candoshi. Gran parte de la población está constituida por huérfanos porque la esperanza de vida es corta y lo era mucho más en el pasado, donde la guerra afectaba sobre todo a los hombres adultos y, por lo tanto, padres de familia. Como si se tratara casi de una figura retórica, muchas historias de vida empiezan por una infancia huérfana y desgraciada: la madre viuda y sus hijos, hambrientos y mal cuidados, buscando desesperadamente una nueva familia. Puesto que se practica el levirato, muchas veces es el hermano del difunto el que se ocupa de la familia huérfana. Pero, en tiempos de guerra -antes- o de escasez - ahora- la penuria de productos alimenticios podía ser grave. Los hermanos del difunto muchas reces no quieren asumir la carga de una nueva familia o lo hacen desganadamente. En este contexto, las historias de vida asocian a los huérfanos humanos con las crías del animal matado o, más concretamente, asocian la adopción de estos huérfanos con la domesticación de las crías, por la familia del cazador. En estas narraciones los huérfanos se presentan efectivamente como un porinclii, es decir un pajarito recién salido del huevo, sin plumas, suplicando al cazador que no lo abandone al destino implacable que la selva le reserva.

La asociación entre domesticación y vida social humana no concierne únicamente a este contexto. Las mujeres, en el momento del matrimonio, son también familiarizadas por sus maridos. He recogido muchas narraciones de estos últimos donde se relata este proceso de familiarización de las jóvenes esposas, casi unas niñas, que pasan a ser de pronto cónỵuges 
de un hombre, hasta entonces un extranjero terrorifico o como mínimo un perfecto desconocido. Las historias relativas a estas bodas forzadas por un arreglo muestran que la pareja pasa por un periodo de «domesticación», si me permiten la expresión, donde el marido intentará progresivamente ganarse el amor de su nueva esposa. Este proceso es llamado también xápshigámaama.

Las mujeres comparten esta configuración afectiva de la familiarización y les gusta presentarse como huérfanas necesitadas del amor y los cuidados del marido para subsistir, de la misma manera que una cría domesticada. Un canto pronunciado por las mujeres abandonadas y destinado a convencer a los esposos de regresar a su hogar conyugal, muestra la idea que el amor, y en concreto el amor conyugal, es percibido como una relación de dependencia compartida.

Esposo, esposo mio, be becho esto para que no me olvides,

En el crepisculo yo pienso en ti y' tú piensas en mi,

Soy' como una buérfana, y' no tengo ganas de comer,

piensa en tu corazón que yo tengo bambre.

Asi se lo dirás a Vacbapa

de esta manera su vientre se removerá de recuerdos, es para bablarle de esta manera que te enrio, tucán.

(Cantado por Marasho, mujer del medio Chapuri, junio del 1994)

Este canto se divide en dos partes. La primera parte es el mensaje que la esposa abandonada quiere transmitir a su esposo, que se encuentra viajando desde hace tiempo. En esta primera parte se habla del crepúsculo, momento que eroca para los Candoshi el amor y sus tristezas, y la mujer le dice a su marido que ha perdido el apetito por lo desgraciada que se siente. La esposa le pide a su marido que piense en el desgano de vivir que ella está sintiendo. En las tres últimas líneas, se dirige al tucán, simbolo del amor en el imaginario candoshi y jibaro en general, quién debe ocuparse de transmitir el mensaje a su marido, Vachapa, para ver si consigue despertarle el deseo de regresar al hogar. 
A las mujeres les gusta imaginar también que sus esposos y sus hijos se sienten ligados a ellas como estos animales familiares que cuidan. La idea de que un hombre dependa de la cocina, los productos de la huerta y, sobre todo, de la cerveza de mandioca que sólo las mujeres pueden producir, aparece tanto en expresiones ordinarias como en el repertorio lírico. En resumidas cuentas, se puede decir que el paradigma de la familiarización nos permite comprender la base conceptual de todas las relaciones afectivas en el seno de la familia candoshi.

Por otro lado, la asociación entre amor y domesticación va más allá del contexto de los vínculos familiares. En un mundo donde las fronteras étnicas $y$ lingüísticas son tan acentuadas y se circunscriben a espacios relativamente pequeños donde las formas de vida cambian considerablemente, la experiencia de la transculturación no es un hecho insólito. No es extraño encontrar candoshi instalados por un tiempo o de manera definitiva entre otros grupos étnicos (Quechua del Pastaza, Cocamilla, etc.), en los pueblos de ribereños hispanohablantes de los grandes ríos o incluso en alguna misión. En todos estos casos, los migrantes pasan por un largo periodo de extrañamiento y adaptación progresivo a la nueva circunstancia. Este esfuerzo de adaptación es comparado al de los animales adoptados y los candoshi esperan de sus anfitriones el mismo cariño que ellos proporcionan a las crías familiarizadas o a otros humanos que se encuentran en esta situación en su casa como, por ejemplo, el antropólogo haciendo trabajo de campo.

Las relaciones con mis anfitriones eran concebidas también desde la óptica de la familiarización, con el fin de atenuar en lo posible mis dificultades de adaptación, muy agudas al principio. Es, sobre todo, en la alimentación que este trabajo discreto pero atento y perseverante se efectuaba. Las mujeres observaban el grado de aceptación de los productos que me ofrecían. En el momento en que, por ejemplo, unos pescados parecían agradarme no era extraño que me los volvieran a ofrecer. Mis anfitriones me hicieron comprender que nuestra relación era similar a la que ellos establecían con los animales domesticados: una relación paternalista, protectora e indulgente 
con mis torpezas. Cuando el atardecer sorprendia nuestras conversaciones, mis anfitriones me confesaban emocionados que me consideraban un ser indefenso en este mundo de la selva y que serían capaces de dar la vida para proteger mi integridad, palabras que dan muestra de una generosidad y nobleza que nunca olvidaré.

El sentido del auto desprecio femenino se encuentra sin duda en esta configuración afectiva que asocia el amor (tanto el conyugal como el amor fraterno o el amor paterno-filial), con la domesticación (en el sentido de familiarización), y la dependencia mutua, que vincula a los miembros de una familia. La mujer se desvaloriza porque es la forma de expresar y suscitar afecto. Puesto que el amor se expresa a través del imaginario de la domesticación, la mujer que canta se sitúa en la posición de un ser vulnerable, en la piel de una pequeña cría cuỵa madre ha muerto y no pide más que ser acogida y cuidada con cariño y ternura. Si la mujer es anciana hablará de su rejez y de las dificultades que la disminución física entraña para su vida. Dicho de otro modo, la mujer se hace querer mostrando una modestia extrema que suscita naturalmente la compasión. Al mismo tiempo, la intérprete de estas canciones recuerda a su marido, hermanos y familiares, a través del masato que sólo ella les puede ofrecer, el vínculo de dependencia mutua que los une, parecida a la de las crías de animales adoptados, dependencia que en la autarquía de la residencia candoshi es fundamental.

Me queda responder a la pregunta expresada en el título del artículo: ¿Por qué el humor nos hace reír?. Obviamente, la respuesta a una cuestión tan general merece un desarrollo que no puedo hacer en el espacio de este artículo; me contentaré nada más en proponer algunos elementos de reflexión. En realidad, esta pregunta es un juego de palabras un tanto provocador que pretende atraer la atención del lector hacia aspectos de la vida social que no han despertado el interés de la antropología porque nos parecen obvios, de sentido común o, incluso, naturales. ¿-Por qué el humor hace reír? El caso etnográfico precedente indica dos aspectos. En primer lugar, y casi no hace falta señalarlo, el humor hace reír si se conoce el contexto cultural donde este humor se produce. Que nos digan que tal persona tiene 
cara de sapo, por ejemplo, nos hace reír porque, como casi en todo el mundo, conocemos el aspecto de este anfibio. Pero si nos dicen que tal persona tiene brazos de maquisapa y no conocemos la anatomía de este primate difícilmente entenderemos el «sentido del humor» de esta comparación. Por otro lado, y esto es menos evidente que lo anterior, lo que hace reír del humor no es a menudo otra cosa que constatar la posibilidad que tiene sólo el humor para decir lo que sería indecible de otra manera. En el caso analizado, aquello indecible, expresado con la imagen del brazo del maquisapa, es la propia filosofía social que vincula entre sí a los parientes y aliados en un flujo de afectos, sin el cual la selva se cerniría inexorablemente sobre ellos.

\section{BIBLIOGRAFÍA}

AMADIO, M.

1983 «Notas sobre ortografia Candoshi» En: A. Corbera (ed) Educación y Lingüística en la Amazonía Peruana. Lima : CAAAP.

1985 "Los Murato: una sintesis bistórica», Amazonía Peruana, 6 (12), pp. 117-131.

AMADIO, M. \& L. D'EMILIO

1983 "La alianza entre los Candoshi Murrato del Alto Amazonas" Amazonía Peruana 5(9), pp. 23-36.

DESCOLA, PH.

1993 "LLes affinités sélectives. Alliance, guerre et prédation dans l'ensemble jiraro", L'Homme, 33 (2-4), pp. 171-190. 
1996 "Constructing natures. Symbolic ecology" and social practice» En: Ph. Descola \& G. Pálsson (eds.) Nature and Society. Anthropological Perspectives. London \& New York : Routledge, pp. 82-102.

\section{SURRALLÉS, A.}

1998 "Entre el pensar y" el sentir. La antropologia frente a las emociones». Anthropológica. $16: 291-304$. Lima.

1999 Au Cœur du Sens. Objectivation et Subjectivation chez les Candoshi de l'Amazonie Péruvienne. Tesis Doctoral. Paris : Ecole des Hautes Études en Sciences Sociales.

2000a «Lapassion génératrice. Prédation, échange et redoublement de mariage candoshi», L'homme, 154-155, pp. 123-144.

2000b «Il 'parlare-collera'. Sul saluto cerimoniale Candoshi» Etnosistemi, 7, pp. $37-46$

TAYLOR, A.C.

1983 "Jivaroan magical sons: achuar anent of connubial love» Amerindia, 8.

1994 "Les bons ennemis et les mau'ais parents. Le traitement symbolique de l'alliance dans les rituels de chasse aux têtes des Shuar (Jivaro) de l'Equateurn. En: Françoise Héritier-Augé \& Elisabeth Coupet-Rougier (eds.) Les Complexités de l'alliance IV. Economie, Politique et Fondements Symboliques. Pp. 73-105. Paris, Editions des archives contemporaines.

1998 "Jivaro Kinship: 'Simple' and 'Complex' 'Formulas: A Dravidian Transformation Group». En: Maurice Godelier, Thomas R. Trautmann \& Franklin E. Tjon Sie Fat (eds.) Transformations of Kinship. Pp. 187-213. Washington and London, Simthsonian Institution Press.

2000 "Le sexe de la proie. Représentations juraro du lien de parenté» L'Homme 154-155:309-336. 
VIVEIROS DE CASTRO, E.

1993 "Alguns aspectos da afinidade no dravidianato amazónico». En Amazonía : Etnologia e História Indígena. Manuela Carneiro da Cunha \& Eduardo Viveiros de Castro, eds. Pp 150-210. São Paulo : Núcleo de História Indígena e do Indigenismo. 